\title{
XAS Investigation of the Fe sites in Phthalate Dioxygenase
}

\author{
H.T. Tsang and J.E. Penner-Hahn \\ Department of Chemistry, University of Michigan, Ann Arbor, MI 48109 \\ C.J. Batie and D.P. Ballou \\ Dept. of Biological Chemistry, Univ. of Michigan, Ann Arbor, MI 48109
}

The phthalate dioxygenase (PDO) from Pseudomonas cepacia catalyzes the dioxygenation of phthalate to a dihydrodiol. PDO contains two Fe atoms in a binuclear site and a third, dissociable iron in a mononuciear site. The binuclear site is a [2Fe-2S] Rieske-like cluster. Rieske-like clusters are spectroscopically distinct from other $\mathrm{Fe} / \mathrm{S}$ clusters, and recent ENDOR measurements have shown that Rieske-like clusters contain at least two nitrogen atoms in place of the more normal thiolate ligands [1]. The mononuclear site is believed to be the site of oxygen activation, however very little is known about the nature of this site. We have used EXAFS spectroscopy to characterize the Rieske-like and the mononuclear sites in PDO. In order to study selectively the Rieske-like site, we measured data for $\mathrm{PDO}$ in which the mononuclear $\mathrm{Fe}$ had been removed. In order to study selectively the mononuclear site, we measured $\mathrm{Zn}$ and Co EXAFS for PDO in which the mononuclear site had been reconstituted with $\mathrm{Zn}$ or Co.

Quantitative curve fitting results for the Rieske-like cluster are given in Table I. These parameters are consistent with those seen for other Fe/S clusters, thus providing the first direct evidence that structural differences do not account for the redox differences between Rieske-like clusters and "normal" [2Fe-2S] clusters. Interestingly, the Rieske-like structure is unaffected (from the EXAFS perspective) by either the metal in the mononuclear site or the binding of substrate.

Curve fitting analysis of the $\mathrm{Zn}$ EXAFS for the $\mathrm{Zn}$ reconstituted protein shows that this site contains predominantly $\mathrm{N}$ or $\mathrm{O}$ ligation and can be well modeled by 6 nitrogens at $2.01 \AA$. On the basis of EXAFS alone it is not possible to distinguish between oxygen and nitrogen ligation, and it is difficult to determine coordination number accurately. However, examination of the structural parameters for known $\mathrm{Zn}$ coordination complexes suggests that a bond length as short as $2.01 \AA$ is only observed for 5 coordinate complexes having predominantly oxygen ligation. Consistent with this interpretation, we see no evidence for the long range structure typical of imidazole nitrogen coordination. Similar results are obtained for the Co EXAFS.

The EXAFS data show no detectable change in mononuclear-site structure when the Rieske-like site is reduced or when substrate is bound. The XANES, however, are quite sensitive to these effects, as shown in Fig. 1. Specifically, there is a decrease in the intensity of the principal absorption maximum for oxidized and substrate-bound forms of the enzyme relative to reduced or substrate-free forms.

The intensity of the 1s-3d transition in the Co XANES spectra can be used as a measure of the distortions of the mononuclear site from a centrosymmetric environment. The $1 \mathrm{~s}->3 \mathrm{~d}$ intensity for Co substituted 
Table I. Curve Fitting For Rieske-like Cluster ${ }^{a}$

$\begin{array}{llrl} & \mathrm{Fe}^{\mathrm{b}} \mathrm{S}^{\mathrm{b}} & \mathrm{Fe}-\mathrm{N}^{\mathrm{b}} & \mathrm{Fe}-\mathrm{Fe}^{\mathrm{b}} \\ \text { Oxidized } & 2.24(3) & 2.05(4) & 2.69(3) \\ \text { Reduced } & 2.28(3) & 2.09(4) & 2.68(3) \\ \Delta \mathrm{R}^{\mathrm{c}} & 0.031(10) & 0 & \\ \Delta \mathrm{s}^{2} & 0.0012(5) & 0 & \end{array}$

a Isolated shells were fit using $3 \mathrm{~S}+1 \mathrm{~N}$ (first shell) or $1 \mathrm{Fe}$ (second shell). Amplitude and phase parameters determined empirically.

b Tabulated numbers are fitted parameters (estimated uncertainties).

c $\Delta R$ and $\Delta s^{2}$ are the change between oxidized and reduced Rieske clusters. These parameters were determined by the phase-difference/amplitude-ratio method.

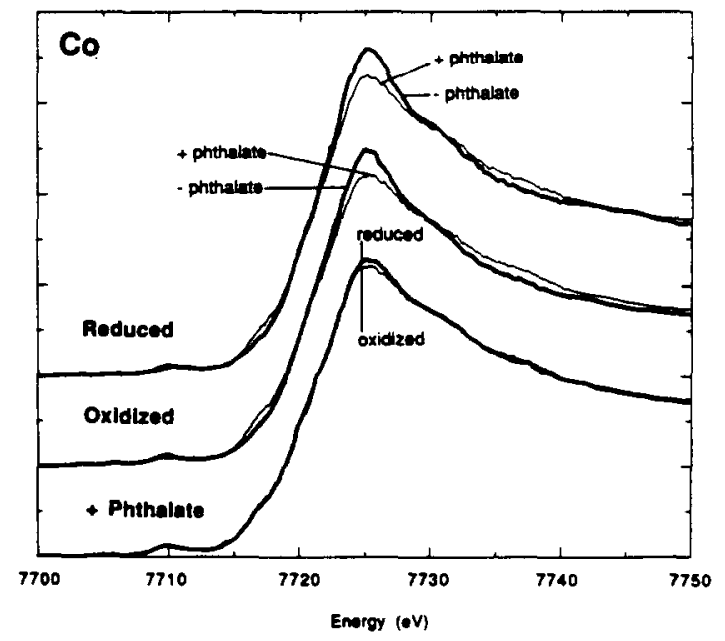

Figure 1. Normalized Co XANES for $2 \mathrm{Fe}+\mathrm{Co}$ PDO. Zn XANES show identical changes.

PDO derivatives is increased on binding substrate or oxidizing the Rieskesite. Absolute intensities are consistent with 5-coordination in the oxidized plus substrate form and 6-coordination in the reduced minus substrate form [3]. Other forms have intermediate 1s-3d intensities, possibly reflecting an equilibrium between these two limiting species. These changes may reflect the protein rearrangements necessary to bind and activate dioxygen.

Acknowledgements. This work was supported in part by the NIH (GM38047) and by the donors of the Petroleum Research Foundation (18073G3,6). JEPH is the recipient of a Camille and Henry Dreyfus Distinguished Young Faculty Award.

1. Cline, J.F.; Hoffman, B.M.; Mims, W.B.; LaHaie, E.; Ballou, D.P.; Fee, J.A., 1985, J. Biol. Chem., 260, 3251-3254.

2. Penner-Hahn, J.E.; Tsang, H.-T.; Batie, C.J.; Ballou, D.P. Manuscript in preparation.

3. Roe, A.L.; Scheider, D.J.; Mayer, R.J.; Pyrz, J.W.; Widom, J.; Que, L. Jr. J. Am. Chem. Soc., 1984, 106, 1676-1681. 